NBER WORKING PAPER SERIES

LAYOFFS, RECALL AND

THE DURATION OF UNEMPLOYMENT

Lawrence Katz

Working Paper No. 1825

NATIONAL BUREAU OF ECONOMIC RESEARCH

1050 Massachusetts Avenue

Cambridge, MA 02138

January 1986

I am especially grateful to Katherine Abraham, Bill Dickens, and Hank Farber for numerous discussions and for comments on previous drafts. I thank John Abowd, Larry Ball, Jeff Harris, John Kennan, Jonathan Leonard, Sherwin Rosen, Lawrence Summers and Robert Topel for helpful discussions. I also appreciate the useful comments of participants in seminars at U.C. Berkeley, the University of Chicago, MIT, NBER, and the University of Rochester. Financial support from the Institute of Industrial Relations and School of Business Administration at U.C. Berkeley, the National Science Foundation, and the Alfred P. Sloan Foundation is gratefully acknowledged. The research reported here is part of the NBER's research program in Labor Studies and project in Government Budgets. Any opinions expressed are those of the author and not those of the National Bureau of Economic Research. 


\section{Layoffs, Recall and the Duration of Unemployment}

\section{ABSTRACT}

This paper shows that the prospect of recall to previous employer is important for a significant number of the unemployed in the United States and that taking into account the possibility of recalls has important implications for the study of unemployment spell durations. A job search model that allows for recalls is shown to lead naturally to a competing risks specification of the distribution of layoff unemployment spell durations in which recall and the taking of a new job are alternate routes for leaving unemployment. A large sample of individual layoff unemployment spell observations derived from the Panel Study of Income Dynamics is analyzed. The common finding for samples containing individuals with nonnegligible recall prospects of an escape rate from unemployment that declines with spell duration is shown to almost entirely result from a declining recall rate. The apparent declining recall rate may be indicative of important uncontrolled heterogeneity rather than true negative duration dependence. Strong positive duration dependence in the new job finding rate is uncovered for UI recipients. Factors raising the likelihood and value of recall appear to depress the new job finding rate. Substantial differences in the distribution of unemployment spell durations are found for UI recipients and nonrecipients. Large positive jumps in both the recall rate and new job finding rate are apparent around the point of UI benefits exhaustion for UI recipients. The results indicate that the potential duration of UI benefits plays an important role in the timing of recalls and of new job acceptances. 


\section{Introduction}

The determination of the factors affecting the length of time spent out of work by unemployed individuals is a matter of considerable significance with important implications for the design and impact of policies such as unemployment compensation and trade adjustment assistance programs. Over the past decade, many studies have attempted to empirically analyze the determinants of individual unemployment spell durations. ${ }^{1}$ Most of these studies have been motivated by job search models which (at least implicitly) focus on the behavior of new entrants to the labor force or workers' permanently displaced from their previous employers with certainty. The possibility of recall to a former job, a process not requiring search, is typically not present in these models. ${ }^{2}$

Yet, in the United States, there is considerable evidence that the prospect of recall is relevant for a substantial number of the unemployed. A significant fraction of workers in manufacturing who lose their jobs are subsequently rehired by their former employers (Feldstein, 1975; Lilien, 1980). Additionally, Barron and Mellow (1979) and Bradshaw and Scholl (1976) show that a substantial number of workers on "temporary" layoff search for alternative jobs during their unemployment spells. BLS monthly figures since 1970 indicate that typically at any point of time only about 15 to 25 percent of job losers on layoff can be classified as workers on fixed-duration layoff with instructions to return to work within 30 days. ${ }^{3}$ The majority of workers on temporary layoff in a cross-section are workers on indefinite layoff.

Further information on the importance of recall prospects is available from a sample of 806 male unemployment insurance (UI) recipients in Missouri and Pennsylvania in 1979-1980. ${ }^{4}$ Each was asked very close to the time of layoff whether he expected to be recalled to his previous employer. Seventy-nine percent of the sample expected to be recalled. Seventy-six percent of those

1. See, for example, Ehrenberg and Oaxaca (1976), Kiefer and Neumann (1979), Lancaster (1979), Narendranatham, Nickell, and Stem (1985), and Solon (1985).

2. Exceptions in the theoretical literature include Burdett and Mortensen (1978), Pissarides (1982), and White (1983). None of these papers takes into account the impact of worker uncertainty about the likelihood of recall on job search behavior.

3. The data from which these figures were derived originated through Bob Bednarzik at the U.S. Department of Labor, Bureau of Labor Statistics.

4. This sample is derived from a data set described in Corson and Nicholson (1983). The specific sample used for these calculations is described and analyzed in detail in Katz (1985). 
who initially expected to be recalled actually had layoff spells ending in recall. Twenty percent of those not expecting to be recalled had spells terminating in recall. These figures suggest that the prospect of recall is relevant for most UI recipients and that some uncertainty concerning their recall chances may be present for a large number of the unemployed.

In this paper. I show that taking into account the possibility of recalls has quite important implications for the empirical study of unemployment spell durations. These considerations have not been adequately treated in previous empirical research. I demonstrate that job search models extended to allow for recalls naturally lead to a competing risks model specification of the distribution of layoff unemployment spell durations in which recall and the taking of a new job are viewed as alternate routes for leaving unemployment. This specification differs sharply from the methods utilized in previous empirical studies of unemployment spell duration. 5

A major implication of the competing risks model specification for layoff unemployment spells is that job search theoretic and UI related factors affecting the reservation wage generate predictions concerning the new job finding rate. These predictions need not necessarilly hold for the typically analyzed overall reemployment hazard since it is a convolution of both the recall rate and the new job finding rate.

Previous empirical analyses of unemployment spell durations utilizing samples including workers with nonnegligible recall prospects, such as Solon (1985) and Clark and Summers (1979), have tended to find that the overall reemployment rate declines with time spent unemployed. One interpretation of this finding is that it is indicative of true negative duartion dependence. This interpretaion potentially casts doubt upon the empirical importance of a large number of standard job search models. ${ }^{6}$ An alternative view is that these results arise from the potentially important bias

5. Previous studies involving the analysis of layoff unemployment spells have used either regression methods or the traditional single risk duration model associated with job searcb models in which the possibility of recalls is excluded. Examples of studies using regression methods include Corson and Nicholson (1983) and Classen (1979). Flinn and Heckman (1982a) provide a convincing critique of the use of regression methods in duration studies. Examples of studies utilizing single risk models include Clark and Summers (1979), Ham and Rea (1985), and Solon (1985). Recalls have typically been treated either by adding a recall dummy as a regressor or by deleting observations with spells ending in recall.

6. Mortensen (1984) and Flinn and Heckman (1982b) discuss a variety of job search models that yield predictions of declining reservation wages and positive duration dependence in the unemployment escape rate. 
caused by unobserved heterogeneity. If some workers because of unobserved factors have lower reemployment probabilities than other seemingly identical workers, they will tend to be unemployed longer. This can generate inferences of spurious negative duration dependence since among observationally identical workers those unemployed longer have lower escape rates. ${ }^{7}$ In fact, these results provide little information concerning the role of job search and UI factors on new job finding since they confound the new job escape rate with the recall rate.

Implementation of the theoretically appropriate competing risks model for layoff unemployment spell durations requires a data set that distinguishes recalls from new job transitions. I have developed and empirically analyzed such a data set containing 1055 layoff unemployment spell observations from Waves 14 and 15 of the Panel Study of Income Dynamics (PSID).

A number of striking findings emerge from this empirical analysis. Strong positive duration dependence in the new job finding rate is found for UI recipients. This result is hidden in single risk models. The shapes of the sample hazard functions differ substantially for UI recipients and nonrecipients. Positive jumps in both the recall hazard and the new job finding rate are found near the point of UI benefits exhaustion for UI recipients. Similar spikes in the hazard functions do not appear for UI nonrecipients. This is strong evidence of an important role of the potential duration of UI benefits in the timing of recalls and of worker new job acceptances.

The paper is organized as follows. A discussion of the implications of job search models extended to take into account the possibility of recalls for the empirical anlaysis of layoff unemployment spells is presented in section II. The data set utilized is described in section III. Section IV contains an analysis of nonparametric sample hazard function estimates. The empirical implementation of both single risk and competing risks specifications with heterogeneity controls is presented in section V. Concluding remarks are found in section VI.

7. Heckman and Singer (1984a, 1984b) and Lancaster (1979) provide discussions of the biases generated by unobserved heterogeneity in duration models. 


\section{Theoretical Background: Job Search with the Possibility of Recall ${ }^{8}$}

In standard job search models, such as the model of McCall (1970), job offers are generated by unemployed workers through costly job search. The probability of leaving unemployment in a small time interval conditional on having been unemployed up to the start of the interval (known as the hazard rate or escape rate) is the product of the probability of receiving a job offer in the interval and the probability that such an offer is acceptable. ${ }^{9}$ These models generate a single risk model of the distribution of unemployment spell durations in which unemployment spells end through the single escape route of the finding of an acceptable new job.

This approach is not appropriate for analyzing workers on layoff with some possibility of recall. An unemployment spell can end for a worker on layoff through either the location of an acceptable new job by search or through recall to the previous employer. The prospect of recall directly affects the overall escape rate from unemployment through the recall rate and indirectly affects it by altering workers' optimal job search strategy. In this section, I analyze how the possibility of recall alters a worker's job search behavior and discuss the implications of taking account the possibility of recall for the statistical distribution of unemployment spell durations.

The job search behavior of workers on layoff can be analyzed in a model that represents an extension of the infinite horizon sationary search model of McCall (1970). ${ }^{10} \mathrm{Jobs}$ for laid-off workers are generated from two sources: (1) recall by the former employer and (2) random search as in the standard McCall model. The worker on layoff makes the dual choice of (a) whether to search for an alternative job, and (b) what reservation wage (or reservation job value) to set in the event of search. In making these decisions, the worker treats the recall probability as a parameter.

The escape rate out of layoff unemployment depends on both the instantaneous probability of recall and on the worker's job-search policy. Recall is generated from a Poisson process with

8. A more detailed and formal analysis of the models discussed in this section can be found in Katz (1985) 9. My discussion in this section concems full-time labor force paricipants who do not leave unemployment through dropping out of the labor force.

10. The model presented here is a modifed continuous-time version of the model developed by Pissarides (1982). Pissarides presents an analysis of firms optimal recall policies as well as an analysis of job search for workers on layoff. 
parameter $p$. Initially, $I$ take $p$ to be known by the worker and constant over time. If instantaneous job search cost $c(c \geq 0)$ is incurred, job offers arrive from a Poisson process with fixed-over-time and known parameter $\lambda$. The probability of receiving a new job offer in the small time interval $b$ is $\lambda h+o(h) .{ }^{11}$ Succesive job offers are independent realizations from a known absolutely continuous lifetime job value distribution $F(J) .{ }^{12}$ The Poisson processes generating recall and alternative job offers are assumed to be independent. ${ }^{13}$

Workers are assumed to be risk neutral, lifetime discounted expected income maximizers. The job value distribution and economic environment are assumed stationary. It is also assumed that once a worker accepts an alternative job, he or she can no longer be recalled to his or her former job. The implications of the relaxation of this assumption are dealt with later on in this section.

The reservation job value, $J^{r}$, is initially assumed to be given. An expression can then be derived for the expected returns from search. If the worker finds it optimal to search, the reservation job value then determines (a) the hazard rate associated with leaving unemployment to a new job and (b) the expected job value in a new job conditional on acceptance $J^{e}$. The individual decides whether to search $(s=1)$ or not to search $(s=0)$ during layoff by comparing the maximized expected returns from the layoff state with search to the expected returns without search.

The following lifetime returns are defined:

$V=$ expected returns during layoff

$u_{o}=$ expected returns from recall to former job

$J^{e}=$ expected returns from new job, after the move has been made.

Workers are assumed to have infinite horizons and to discount future incomes at constant rate $r$. In calculating lifetime returns, workers take into account the following additional exogenous variables:

11. o(b) is defined to be a term such that $\lim _{h \rightarrow 0}(o(h) / h) \rightarrow 0$

12. Workers are assumed to have positive discount rates so that lifetime expected job value is a well-defined concept. If workers can be laid off from their jobs. it reduces the algebra greatl? to work with lifetime job values rather than explicitly writing down expressions for the value of new jobs and dealing with reservation wages.

13. This assumption means the analysis in this section should be viewed as pertaining to movements in $p$ and $\lambda$ afier controlling the common local and aggregate local market conditions. The independence assumpton is then plausible in the case where acceptance of a new job precludes future recall to a worker's previous job. 
$b=$ instantaneous unemployment compensation, paid throughout unemployment spell

$\mathrm{m}=$ once-for-all cost of changing jobs

$w_{o}=$ instantaneous wage on former job.

The expected returns from layoff can be written as

$$
V=\frac{(b-s c) h}{1+r h}+\frac{p h}{1+r h} W_{o}+\frac{q s \lambda h}{1+r h}\left(J^{e}-m\right)+\frac{(1-(p+q \lambda s) h)}{1+r h} V
$$

where

$$
q=\int_{J^{\prime}}^{\bar{J}} f(J) d J \text { and } J^{e}=\frac{1}{q} \int_{J^{\prime}}^{\bar{J}} J f(J) d J .
$$

The first term on the right side of (1) is the discounted value of unemployment compensation net of expected search costs over interval h. The second term is the probability of recall times the discounted value of recall. The third term is the discounted expected value of job change multiplied by the probability of job change in interval $h$. The final term is the discounted value of remaining on layoff times the probability of still being on layoff after h. $\bar{J}$ is the upper boundary of the support of the lifetime job value distribution. $q$ is the probability that a new job offer is acceptable.

The value of recall, $W_{o}$, is given by

$$
W_{o}=w_{o} \frac{h}{1+r h}+\frac{d h}{1+r h} V+\frac{(1-d h)}{1+r h} W_{o}
$$

where layoffs are assumed to come from a Poisson process with parameter $d$. This expression is based on the assumption that if a worker is recalled he or she is recalled to his or her former job at the former wage. It is also assumed that workers prefer recall to the unemployment state.

Taking the limit as $h \rightarrow 0$ and eliminating $W_{o}$ in (1) using (2), one can solve for $\mathrm{V}$ yielding

$$
V=k\left[b-s c+\frac{p}{r+d} w_{0}+\lambda q s\left(J^{e}-m\right)\right]
$$

where

$$
k=\frac{r+d}{r(r+d+p)+\lambda q s(r+d)} .
$$

The worker chooses the reservation job value $J^{r}$ to maximize $\mathrm{V}$ given $s=1(\mathrm{~V}(\mathrm{~s}=1))$. The worker then compares the value of $\mathrm{V}(\mathrm{s}=1)$ at the optimum reservation job value to $\mathrm{V}(\mathrm{s}=0)$, the 
expected returns from the layoff state with no search, for the purpose of determining whether to search or not to search.

The first-order condition for the optimal reservation job value can be written as

$$
\frac{\partial V(s=1)}{\partial J^{r}}=k s \lambda f\left(J^{r}\right)\left[-J^{r}+m+V(s=1)\right]=0
$$

This means that $\frac{\partial V^{\prime}(s=1)}{\partial J^{r}}=0$ at

$$
J^{r}=V(s=1)+m
$$

At this point, $\frac{\partial^{2} V(s=1)}{\partial\left(J^{r}\right)^{2}}<0$, so the reservation job value that satisfies (4) is the unique value that maximizes (3) given $s=1$.

The reservation job value accords with intuition. The worker chooses $J^{r}$ such that after being compensated for moving costs, the worker is indifferent between continued layoff unemployment and having a job with value $J^{r}$.

The reservation job value increases with the recall arrival rate parameter $\mathrm{p}$. This can be seen by differentiating $J^{r}$ with respect to $\mathrm{p}$ :

$$
\frac{\partial J^{r}}{\partial p}=\frac{\partial V(s=1)}{\partial p}>0
$$

The reservation job value (or reservation wage) also rises with declines in job search and job changing costs and with increases in the wage at the current job and the level of the unemployment insurance benefit.

The next issue is whether the worker finds it optimal to search during layoff $(s=1)$ or simply to wait for recall $(s=0)$. The decision whether to search or not depends on the recall arrival rate $p$. Katz (1985) shows that two cases arise in the search choice problem. In the first case, there exists a unique recall arrival rate $p^{o}$, such that if $\mathrm{p}>p^{o}$, the individual will not search during layoff, but if $\mathrm{p}<p^{o}$, he or she will search. The second case can arise if search costs are quite small or nonexistent. In this case, the worker searches for all values of $p$. In both cases, the new job finding rate declines in $\mathrm{p}$ since the reservation job value rises with $\mathrm{p}$. Better recall prospects reduce the new job 
escape rate. The key theoretical prediction is that the new job escape rate is negatively related to the recall probability.

The analysis so far has assumed that if a worker accepts a new job, he or she is precluded from receiving a future recall offer to his or her previous job. The structure of the layoff-recall process in the United States is not always consistent with this assumption. In fact. unless a worker relocates or moves out of contact with his previous employer, acceptance of a new potentially temporary job need not affect the worker's recall chances. It is shown in Katz (1985) that the basic theoretical result that the new job finding rate is depressed by better recall prospects continues to hold, under reasonable assumptions, when the model is altered to the other extreme by assuming that taking a new job has no effect on an individual's recall prospects.

The recent empirical work of Topel $(1983 ; 1984)$ suggests that the unemployment insurance system has its strongest impact in increasing the incidence of temporary layoff unemployment. The model presented here suggests the unemployment insurance system may do this by allowing firms to layoff workers with a smaller chance of losing them to alternative employers.

I turn now to the statistical implications of the model. The statistical model of layoff spell durations generated by the theory is a competing risks model of the type frequently used in the failure time analysis literature. ${ }^{14}$ Layoff spells can end either through recall or through the finding of an acceptable alternative job. There are two competing exit routes or risks, and whichever risk occurs first terminates the unemployment spell. The competing risks literature approaches problems of this sort by defining latent failure times corresponding to each failure type. Let $T$, be the latent failure time until recall and let $T_{n}$ be the latent failure until new job acceptance. The actual unemployment spell duration $T_{u}$ is then given by

$$
T_{u}=\min \left(T_{r}, T_{n}\right)
$$

The probability that a layoff unemployment spell $T_{u}$ exceeds $t$ depends on the probability of no recall before $t$ and of no acceptable new job offer arriving before $t$. A consequence of the

14. Kalbfleisch and Prentice (1980) provide a detailed discussion of the competing risks model. Flinn and Heckman (1982b) and Farber (1980) present examples of labor market models that yield competing risks specifications. 
Poisson process arrival assumptions is that each of the random variables $T_{r}$ and $T_{n}$ has an exponential distribution. The survivor function $P\left(T_{u} \geq t\right)$ can be written as

$$
P\left(T_{u} \geq t\right)=P\left(T_{r} \geq t, T_{n} \geq t\right)=\exp (-(p+\lambda s q)) .
$$

The overall escape rate (hazard rate) from unemployment is

$$
h(t)=-\frac{d \ln p\left(T_{u} \geq t\right)}{d t}=p+\lambda s q .
$$

This stationary model yields no duration dependence (i.e. a constant hazard rate over time). The cause-specific hazard functions related to the recall and new job escape routes are

$$
h_{r}(t)=p
$$

and

$$
h_{n}(t)=\lambda s\left(1-F\left(J^{r}\right)\right) .15
$$

The expected duration of unemployment is is $1 /(p+\lambda s q)$.

I have assumed so far that the recall probability is known by the worker. This is not always realistic. Workers often cannot immediately tell if layoffs arising from reduced demand at the level of the firm represent a temporary phenomenon or a permanent shift in the firm's level of demand. It may take a while for workers and firms to realize that a layoff is likely to be permanent. Thus, it seems likely, holding other factors constant, that the longer a worker is unemployed without recall, the less likely he or she will perceive his or her recall prospects to be.

Katz (1985) has formalized this notion in a model of layoff unemployment in which workers are uncertain of their recall prospects and learn about them over the course of their unemployment spells in a Bayesian manner. In this model, a worker on layoff forms initial beliefs about his or her instantaneous recall probability $\mathrm{p}$ using past experience and observation of market conditions. These beliefs about $\mathrm{p}$ are summarized by a prior density function. In a discrete time formulation, each period the worker is on layoff he or she is either recalled or not recalled. Workers remaining 15. The cause specific hazards are defined as

$$
h_{j}(t)=\lim _{\leftrightarrow \rightarrow 0} \frac{P\left(t<T_{u}<t+\epsilon, J=j \mid T_{u}>t\right)}{\epsilon}
$$

where $j=r, n$ and $J$ is the mode of failure. 
unemployed must have received no recall draws in each previous period of unemployment. Each no recall draw leads a worker to revise downward his or her beliefs about the likelihood of recall. The perceived recall probability declines with duration of unemployment since the longer the spell the more no recall draws encountered. The model generates a declining reservation job value as the duration of unemployment increases. The probability that a worker searches increases with unemployment duration. The learning model generates a new job hazard with positive duration dependence and yields a declining reservation wage.

The standard infinite horizon, stationary environment search model with no recalls yields an optimal search strategy that is stationary (i.e. a constant reservation wage). A number of modifications to this standard model generate positive duration dependence even without allowing for recalls. For example, liquidity constraints (Mortensen, 1984) generate a reservation wage that declines with time spent unemployed. The limited potential duration of unemployment insurance (UI) benefits can generate positive duration dependence in the new job hazard up to the point of benefits exhaustion (Mortensen, 1977). Alternatively, stigma in the labor market attached to extended joblessness and worker discouragement can yield tendencies towards negative duration dependence. The addition of the possibility of recall with uncertainty about the recall probability can also generate a declining reservation wage.

The important point is that the job search factors which impact on reservation wage policies listed above all generate implications concerning the new job escape rate. These need not necessarilly translate into equivalent predictions for the overall escape rate from unemployment for workers with nonnegligible recall prospects. Thus, findings of negative duration dependence in single risk models for samples including workers for whom recall is a possibility (e.g. Solon, 1985; Clark and Summers, 1979) need not imply rejections of the importance of learning about recall or of job search factors.

\section{Data Description}

Existing samples of individual level unemployment spell data are quite incomplete and almost 
all fail to distinguish recalls from new job exits. Still, a large sample of layoff unemployment spells that distinguishes recalls from new job exits can be extracted from Waves 14 and 15 of the Panel Study of Income Dynamics (PSID). ${ }^{16}$ These two waves of the PSID have detailed questions on the previous year's unemployment experience of household heads. I can determine for the head's last unemployment spell in the previous year: the spell duration in weeks, how the spell was initiated, and whether it ended through recall, ended through the taking of a new job or was censored at the interview date. The relevant questions were only asked of labor force participants at the time of the interview.

The unit of observation that I utilize is the unemployment spell. The necessary information is available only for household heads, and for each household head the relevant data exist only for the head's last unemployment spell at least partially contained in 1980 and his or her last spell at least partially contained in 1981. A last spell of unemployment from the previous year made it into my sample if it satisfied the following conditions:

1. the head at the time of interview was head previous year;

and

2. (a) the spell ended in recall to the previous employer;

or

(b) the spell ended with a new job transition and the previous job separation was initiated by a layoff or firing;

or

(c) the spell is censored and the head lists self at next interview as on temporary layoff at the time of the interview or lists self as unemployed having separated from last job by layoff or firing.

The PSID does not distinguish between job separations through layoffs and through firings, although it does allow one to distinguish other routes of job separation such as quits and plant closings from

16. A description of the PSID can be found in Survey Researcb Center (1984). A more detailed discussion of the construction and basic characteristics of the sample used in this study is available in Katz (1985). 
layoffs and firings. Thus, some discharged workers will be included in my data set. Since both BLS manufacturing turnover data and CPS unemployment data indicate that layoffs are far more numerous than firings (discharges for cause), this should not be a big problem.

A potential problem with this data set is that the PSID provides information only on an individual's last unemployment spell at least somewhat overlapping the year previous to an interview. This sampling scheme is likely to oversample longer unemployment spells. In a two state model of employment and unemployment in which the transition probabilities are independent processes, the sampling procedure of picking only an individual's last spell overlapping the sampling time frame oversamples longer spells, downward biases the estimates of the unemployment to employment transition probability and upward biases estimates of expected unemployment spell duration. These results are demonstrated in the appendix to this paper. The effects are less clear when the transition probabilities from employment to unemployment and from unemployment to employment are not independent. It seems possible that estimates from this data set tend to overestimate expected unemployment spell durations and underestimate the hazard rates. It is also shown in the appendix that this sampling frame can generate spurious inferences of positive duration dependence for unemployment spells. Yet, when employment spells tend to be longer than unemployment spells, the degree of positive duration dependence spuriously generated by the sampling scheme cannot be very large. It appears quite unlikely that the degree of positive duration dependence in the new job hazard estimates presented later in this paper could be the spurious result of the initial conditions problem associated with the sampling mechanism. This claim is supported by the fact that my duration dependence parameter estimates for a single risk model using this data set are extremely close to those reported by Solon (1985) for a data set without this sampling frame difficulty.

The actual sample utilized in my empirical work is restricted to observations for individuals over 20 and under 65 years old and deletes observations for which relevant data are missing. This leaves a layoff unemployment spell data set of 1055 observations. Variable definitions and means and standard deviations of the data are presented in Table $1 .{ }^{17}$

17. The means of the data in Table 1 indicate that the sample is not a random sample of the layoff unemployed population. A major reason for this is that the PSID oversamples low income housebolds. The extremely high 
The PSID data have two potential weaknesses. The first is that while information is available on whether an individual received unemployment insurance (UI) at some point during his or her unemployment spell, there is not adequate information to compute the replacement rate or weekly benefit level relevant for that particular spell. In the second place, job tenure data for the job from which the unemployment spell initated is not directly available for many of the spells in the sasuple. ${ }^{18}$ Job tenure impacts are analyzed using the sub-sample of the PSID which contains job tenure information.

The information in Table 1 reveals that 57 percent of the spells in the sample end in recall, and 23 percent end in the taking of a new job. The remaining 20 percent of the spells in the sample are censored at the date of the interview. The mean observed spell duration of 17.34 weeks in Table 1 is not the mean of the completed spell durations since it includes the censored spell durations.

An easy way to get a handle on the mean completed spell duration and the proportion of spells predicted to eventually terminate with recall is to estimate a simple competing risks model with no heterogeneity and no duration dependence allowed. This is the statistical model generated by the basic theoretical model in a stationary environment presented in section II. I specify the causespecific hazard $\left(h_{r}\right)$ and new job hazard $\left(h_{n}\right)$ as constants with $h_{r}=p$ and $h_{n}=\lambda$. This specification of the hazard functions means the probability of an unemployment spell lasting at least till $t$ (the survivor function) is simply $\exp (-(\lambda+p) t)$.

The maximum likelihood estimates of $p$ and $\lambda$ for the basic data set are $\hat{p}=.03297$ and $\hat{\lambda}=$ .01340. This yields an expected unemployment duration in the sample of $1 /(\hat{\lambda}+\hat{p})=21.57$ weeks.

nonwhite proportion of the sample results from this sampling scheme. One potential solution to this problem would be to delete the observations from the "poverty" (original Census) sample in the PSID and use only observations from the "random" (original SRC cross-section) sample part of the PSID. This procedure would eliminate about half of the data set. I have estimated the basic empirical specifications discussed in this paper for the entire sample, the "random" sample, and for a sample consisting only of married prime age males (ages 25 to 55). The empirical results concerning the shapes of the hazard functions and the effects of independent variables on layoff spell durations are qualitatively almost identical for all three of these groupings. I stick to analyzing the results for the larger data set.

18. Job tenure information is directly available only for spells recorded in the Wave 15 interview. Among the spells from Wave 15 , the information is only available if the individual were employed at the time of the previous year's interview. The sample with job tenure information suffers from a sample selection problem with the sampling scheme quite dependent on the previous year's unemployment experience. 
The predicted proportion of spells eventually ending in recall is $\hat{p} /(\hat{\lambda}+\hat{p})=.7110$. This recall proportion is quite similar to the rehire rates for temporary layoffs in manufacturing estimated by Lilien (1980). Still, spells ending in recall account for only 53.3 percent of the total weeks of unemployment among the completed spells in my sample. The overall share of weeks of layoff unemployment accounted for by spells ending in recall is likely to be much smaller since, dropping the assumptions of homogeneity and constant duration dependence, not many of the long censored spells in the sample are likely to have ended in recall.

There are sharp differences in the characteristics of UI recipients and UI nonrecipients in the PSID data set. UI benefits were received for at least some part of the unemployment spell in 63.6 percent of the observations. Workers in the UI recipient group are more likely to be white, to be married, to be male, and to have been laid-off from a manufacturing firm. The UI nonrecipients appear much more so than the UI recipients to be made up of low-income, "disadvantaged" workers with labor market difficulties. This is not surprising since workers with unstable labor force histories are those most likely to fail to qualify for UI benefits. Additionally, workers discharged for cause will tend to show up in the nonrecipient group.

\section{Sample Hazard Functions for the PSID Data}

A basic tool for the analysis of duration data is the sample hazard function. Nonparametric hazard function estimates with no heterogeneity controls are presented in this section for the entire sample and for the UI recipients and UI nonrecipients sub-samples. The weekly duration data is grouped into four week intervals in this section for ease of presentation.

The hazard function estimates shown in Tables 2, 3, and 4 are based on the Kaplan-Meier nonparametric hazard function estimator. ${ }^{19}$ The Kaplan-Meier estimator of the hazard function for a particular period is simply the number of escapes in the period divided by the population at risk at the start of the period. The cause-specific hazard function estimators are analogously defined replacing total escapes by the cause-specific escapes.

19. Kalbfleisch and Prentice (1980) discuss the properties of the Kaplan-Mejer estimator. 
The sample hazard estimates for the entire sample are presented in Table 2 and plotted in Figure 1. The overall unemployment hazard is downward sloping with a sharp initial drop after the first month and positive spikes at 25-28 weeks, 37-40 weeks, and 49-52 weeks. The overall unemployment hazard submerges sharp differences in the recall and new job hazard functions. The downward slope of the unemployment hazard results from the recall hazard component. Most recalls occur within 1 to 2 months. The new job hazard function is slightly upward sloping up to about 40 weeks.

An interesting feature of both the new job and recall hazard functions shown in Figure 1 is that they both exhibit substantial positive jumps at $25-28$ weeks and $37-40$ weeks. In the weekly data, these jumps are almost completely accounted for by the large number of recalls and new job exits reported at 26 weeks and at 39 weeks. The exact placing of these spikes is not surprising since Sider (1985) reports that a widespread response bias in surveys collecting information on previous unemployment experience is the tendency for fairly long spell durations to be reported as lasting exactly half a year ( 26 weeks), three quarters ( 39 weeks), or one year (52 weeks). The importance of these jumps is suggested by the differences in the shapes of hazard functions for the UI recipient and nonrecipient groups.

The sample hazard function estimates for the UI recipient and UI nonrecipient samples are presented in Tables 3 and 4 and graphed in Figures 2 and 3. One striking feature of these estimates is that the 26 week and 39 week recall hazard spikes and new job hazard upward shifts are quite pronounced in the UI recipient sample and nonexistent in the UI nonrecipient sample. ${ }^{20}$ It is hard to believe that there are important enough systematic differences between the UI and no UI sample in the likelihood of an individual misreporting his spell length as around 26 or 39 weeks to explain these dramatic differences in the sample hazard functions. The upward movements in the recall and new job hazards near the 26 and 39 week points for UI recipients appear to be real phenomena related to the limited duration of UI benefits in the United States. The potential UI benefits dura-

20. The Kaplan-Meier estimated asymptotic standard errors for the sample hazard functions indicate that these jumps are statistically significant at conventional significance levels. 
tion for qualified workers in most states is typically close to or exactly 26 weeks in normal times. When extended benefits are in effect, the potential UI benefits duration for qualified workers is typically 39 weeks.

The overall shapes of the sample hazard functions are quite different for the UI and no UI samples. The UI recipient sample new job hazard function starts out much lower and is much more upward sloping than the Ul nonrecipients new job hazard function. The major difference between the new job hazards for the two groups in the first month might be related to the one week waiting period before UI benefits eligibility in most states and the possibility that eligible workers anticipating short spells don't apply for benefits and end up in the nonrecipients sample. These factors could not account for the major differences in the sample hazards for the two groups beyond the first interval.

One possible explanation for the differences in the UI and no UI groups hazards is that workers who receive UI are better able to wait for a potential recall offer and can afford to be more selective concerning new job opportunities than those who don't receive UI. Additionally, workers receiving UI may have a higher value and greater likelihood of recall overall. For the sub-sample of 395 observations for which length of service (tenure) at previous employer data is available, the average seniority for UI recipients is 5.6 years as opposed to 3.9 years for nonrecipients.

The jumps in both the recall and new job hazards at 26 weeks and 39 weeks for UI recipients appear to be closely related to the potential duration of UI benefits. The rules concerning UI benefit duration differ greatly across states. There was a uniform potential duration of 26 weeks in ten states during the sample period. In the other states, the maximum duration of benefits was typically 26 weeks (and somewhat higher in a few states) although some workers could qualify for fewer weeks of benefits (Unemployment Benefit Advisors, 1982). Additionally, federally subsidized extended benefits of 13 weeks (up to a maximum of 39 weeks of benefits collection) were triggered in a particular state if that state's insured unemployment rate for the previous 13-week period were above a specified threshold level. Extended benefits could also be triggered nationally when the national insured unemployment rate was persistently above a threshhold value. 
Information from the PSID on the start dates of unemployment spells and workers' states of residence was combined with information on periods in which extended benefits were available for each state (U.S. Department of Labor, 1983) to determine for each unemployment spell located near the 26 and 39 week spikes whether it occurred in a period in which the worker could have been eligible for extended benefits. Practically all the UI recipient unemployment spells terminating around 39 weeks occurred in states and periods in which extended benefits were triggered. On the other hand, three appears to be an even split among the 34 spells at the 26 week spike between locations and times with and without extended benefits triggered. Given the response bias towards the reporting of 26 week spells, these results seem supportive of the implication that both the recall and new job finding rates for UI recipients are relatively high in the period around when benefits are exhausted.

There are a number of potential explanations for the increase in the recall rate around the time of UI benefits exhaustion and the sharp decline in recalls after benefits exhaustion. One explanation is an implicit contract type explanation such as in the model of Feldstein (1976). Imperfectly experience-rated firms and their workers may extensively use the UI system in downturns to the firm's demand. One potential type of utilization would be a rotating system of layoffs in which workers who exhaust their UI benefits may be recalled and other workers still eligible for benefits laid off in their place. Seniority layoff systems and efficiency wage considerations might hinder the ability of firms to rotate layoffs across workers. There does not appear to be much evidence of rotating layoffs systems in the United States. Still, firms expecting recall within a reasonable horizon might recall workers close to when benefits run out rather than potentially lose them to new jobs.

The increase in the new job hazard starting at 26 weeks for UI recipients is likely to reflect two main factors relating to UI exhaustion. The first is the explanation of the standard search model in which potential recall prospects are ignored. Mortensen (1977) has analyzed such a model in which the unemployment exit hazard rises as the date of UI exhaustion approaches and then levels out at the new higher level after UI benefits have run out. The second factor is that given the behavior of 
the frm discussed above, the event of no recall before LI benefits are exhausted is a good signal to the worker that his future recall chances are quite slim. This will stimulate an increased new job hazard from the lower reservation wage and greater search intensity induced by a drop in perceived recall prospects. A learning model of search bebavior with uncertain recall prospects combined with limited UI duration provides a coherent explanation for the shape of the new job hazard function associated with the UI recipient group and the differences in the distribution of spell durations for UI recipients and nonrecipients.

\section{Econometric Specification and Estimation: The PSID Data}

In this section, I control for observed variables in estimating parametric modeis of layoff unemployment spell durations. The parmaeter estimates for the control variables indicate how individual. industry, and labor market characteristics affect individual variation in unemployment spell durations. Competing risks model estimates indicate bow these factors impact on the recall and new job finding rates. The differences in the empirical results for single risk and competing risks models indicate the problems in making inferences about layoff unemployment spell durations from traditional single risk model estimates.

The issue of the potential impacts of unobserved beterogeneity on the estimates needs to be discussed. A number of techniques have been developed in recent years to handle the difficulties created by unobserved beterogeneity in duration models. ${ }^{21}$ One method is to assume that the unobserved heterogeneity components are drawn from a certain parametric distribution. Still, Heckman and Singer (1984b) demostrate that an incorrect assumption about the parametric form of the distribution of unobserved heterogeneity components can lead to grossly incortect inferences about duration dependence. Heckman and Singer strongly recommend the use of nonparametric methods. Although some progress bas been made in designing nonparametric methods to deal with unobserved heterogeneity, these methods are still in their infancy especially with respect to empirical implementation in a competing risks framework. I stick with estimates that are based upon the

21. Heckman and Singer (1984a, 1984b) provide excellent discussions of the potential biases generated by unobserved beterogeneity and techniques for dealing with these problems. 
inclusion of a large number of observed heterogeneity controls and with no explicit control for unobserved heterogeneity since the direction of bias in the duration parameter is known to be towards negative duration dependence in this case. Findings of positive duration dependence in the new job hazard under these conditions are indicative of "true" positive duration dependence.

I first turn to the estimation of a traditional single risk model of unemployment spell duration. A specification of the hazard function determines the distribution of spell durations. I utilize the proportional hazards model of Cox (1972). The hazard function for an individual $i$ with regressors $X_{1}$ is specified as

$$
h\left(t, X_{l}\right)=h_{o}(t) * \exp \left(X_{i} \Pi\right)
$$

where $\Pi$ is a parameter vector.

Following Lancaster (1979) and Solon (1985), I specify the base-line hazard $h_{o}(t)$ as

$$
h_{o}(t)=u t^{u-1}, u>0 \text {. }
$$

This yields a Weibull duration model. The hazard function displays positive (negative) duration dependence if $u>1(u<1)$ and no duration dependence if $u=1$.

Maximum likelihood estimates of this Weibull specification of the single risk model with observed heterogeneity controls for both the UI recipient and UI nonrecipient samples are presented in Table 5. The Weibull duration parameter estimate of .85 for the UI recipient sample is extremely close to the estimate of .80 reported by Solon (1985) for a single risk Weibull model applied to a sample of UI recipients from Georgia in 1978-79. The potential bias of unobserved heterogeneity means the duration parameter estimates are inconclusive with respect to the nature of "true" state dependence. The closeness of the duration estimate to that of Solon's indicates that the bias induced by the PSID sampling scheme is not serious.

The estimates presented in Table 5 for both groups indicate that nonwhites and females have longer layoff unemployment spells. The estimates of the single risk model are difficult to analyze since they do not allow one to determine a variable's impacts in spell duration through its effect on recall prospects and on new job finding. A competing risks model is needed to gain insight into how 
recall prospects and search theoretic factors influence layoff unemployment spell durations.

I now turn to the competing risks model specification. A specification of the recall and new job cause-specific hazard rates determines the survivor function in a competing risks model. ${ }^{22}$ I utilize a Weibull version of the proportional hazards specification of the cause-specific hazards. The recall and new job cause-specific hazard functions for an individual i with regressor variables $X_{i}$ are specified as

$$
h_{r}=a t^{a-1} e^{X_{i} \beta}, a>0
$$

and

$$
h_{n}=b t^{b-1} e^{X_{i} \gamma}, b>0
$$

where $\beta$ and $\gamma$ are parameter vectors.

The probability of an unemployment spell $T_{u i}$ lasting to at least $\mathrm{t}$ for an individual $\mathrm{i}$ is the joint probability of both the latent recall duration $T_{r i}$ and latent new job duration $T_{n i}$ both lasting to at least $\mathrm{t}$. The survivor function is given by

$$
G\left(t, X_{i}\right)=P\left(T_{u i} \geq t\right)=\exp \left[-\int_{0}^{t} h\left(u, X_{i}\right) d u\right]
$$

where $h\left(t, X_{i}\right)=h_{r}\left(t, X_{i}\right)+h_{n}\left(t, X_{i}\right)$. Substituting for $h\left(t, X_{t}\right)$ from (8) and (9) yields

$$
G\left(t, X_{i}\right)=\exp \left(-e^{X_{i} \beta} t^{a}\right) \exp \left(-e^{x_{i} \gamma} t^{b}\right) .
$$

The likelihood function for the sample follows directly from the specification of the causespecific hazards and the resulting survivor function. The contribution to the likelihood function for an individual recalled after a spell duration of $t_{i}$ is $P\left(T_{n i}=t_{i}, T_{n i} \geq t_{i}\right)$. Thus, the contribution for an individual recalled at $t_{i}$ is the product of the recall hazard and survivor function at $t_{i}$ :

$$
L_{i}=h_{r}\left(t_{i}, X_{i}\right)^{*} G\left(t_{i}, X_{i}\right) .
$$

The contribution to the likelihood function for an individual leaving unemployment through the taking of a new job at $t_{i}$ is analogously given by

22. Kalbfleisch and Prentice (1980) discuss the difference between a cause-specific hazard and the hazard associated with the marginal spell distribution of a particular failure mode in a model with competing risks. 


$$
L_{i}=h_{n}\left(t_{i}, X_{i}\right)^{*} G\left(t_{i}, X_{i}\right) .
$$

The contribution to the likelihood function for an individual censored at $t_{i}$ is simply the probability that both the new job and recall hypothetical durations are greater than $t_{i}$ :

$$
L_{i}=G\left(t_{i}, X_{i}\right)
$$

In a sample of $\mathrm{N}$ spells, where the first $k_{1}$ end in recall, the next $k_{2}$ end in new jobs, and the remaining are censored, the overall log likelihood function can be written as

$$
\ln L=\ln L_{r}+\ln L_{n}
$$

where

$$
\begin{aligned}
& \ln L_{r}=k_{1} \ln a+\sum_{1}^{k_{1}}\left[(a-1) \ln t_{i}+X_{i} \beta\right]-\sum_{1}^{N} e^{X_{i} \beta} t_{i}^{a} \\
& \ln L_{n}=k_{2} \ln b+\sum_{k_{1}+1}^{k_{1}+k_{2}}\left[(b-1) \ln t_{i}+X_{i} \gamma\right]-\sum_{1}^{N} e^{X_{i} \gamma} t_{i}^{b} .
\end{aligned}
$$

The likelihood function can be broken up into two factors. The first component $L_{r}$ depends only on the parameters of the recall hazard, and the second $L_{n}$ depends only on the new job hazard parameters.

Maximum likelihood estimates of the proportional hazards version of the competing risks model with extensive observed heterogeneity controls are presented in Tables 6 and 7 for the UI sample and the UI nonrecipient sample. The UI sample exhibits strong positive duration dependence in the new job hazard. The elasticity of the new job hazard with respect to unemployment duration is estimated as .44 . In the no UI sample, there appears to be negative duration dependence in the new job hazard, although the hypothesis of no duration dependence cannot be rejected.

If the spikes in the sample hazard functions at 26 and 39 weeks for UI recipients are viewed as discrete events at the UI exhaustion points rather than as indicative of a smoother increase in the escape rate around when UI benefits run out, a more flexible specification of the hazards than the Weibull specification in equations (8) and (9) is apropriate. One approach is to augment the 
Weibull specification to allow discrete jumps in the hazard rate in the one week intervals with exactly 26 and 39 weeks as midpoints. This implies a new job cause-specific hazard of the form

$$
h_{n}\left(t, X_{l}\right)= \begin{cases}b t^{b-1} \exp \left(X_{\imath} \gamma\right) & 0<t<25.5 \\ b t^{b-1} \exp \left(X_{i} \gamma\right) \exp \left(\pi_{1}\right) & 25.5 \leq t \leq 26.5 \\ b t^{b-1} \exp \left(X_{i} \gamma\right) & 26.5<t<38.5 \\ b t^{b-1} \exp \left(X_{i} \gamma\right) \exp \left(\pi_{2}\right) & 38.5 \leq t \leq 39.5 \\ b t^{b-1} \exp \left(X_{\imath} \gamma\right) & 39.5<t\end{cases}
$$

where $\pi_{1}$ and $\pi_{2}$ are the 26 and 39 week spike parameters. The recall hazard is analogously defined. Estimates of the duration and spike parameters for this modified Weibull specification applied to the UI recipients sample are shown in Table 8 . The basic finding of strong positive duration dependence in the new job hazard is not altered with a duration parameter estimate of 1.37 . The 26 week spikes are large and quite significant for both the recall and new job hazards. The estimates of the heterogeneity control parmeters are almost identical to those of Table 6.

Returning to the estimates presented in Tables 6 and 7, one observes that an increase in age appears to raise the recall hazard and reduce the new job hazard. This effect may actually be a proxy for increased job tenure (or seniority) which potentially raises the value of and probability of recall. When the basic Weibull model is estimated on the sub-sample (UI and no UI) of 395 observations for which information is available on length of employment at the firm from which the worker was laid off, the age effect for both the recall and new job hazards becomes quite insignificant. Tenure at previous employer has a strong positive effect on the recall hazard and an even stronger negative effect on the new job hazard. The major features of the estimates on the tenure sub-sample are presented in Table 9. These estimates indicate that a 1 year increase in tenure at the job from which a worker is laid off raises his or her recall hazard by approximately 7.2 percent and reduces his or her new job hazard by about 17.1 percent. This implies that a factor presumably raising the gains from recall serves to sharply reduce the new job hazard.

The estimates in Table 9 indicate that UI appears to be associated with longer unemployment spells once seniority (or job tenure) affects are taken into account. The hypotheses that the recall and new job hazards of the UI recipient and nonrecipients groups are the same or differ in only the 
constant terms can be rejected at any reasonable significance level through likelihood ratio tests for both the entire sample and the job tenure sub-sample.

I turn now to the impact of the other heterogeneity variables on layoff spell durations. I shall focus on the estimates for the UI recipient sample presented in Table 6. For both the new job and the recall hazard rates, one can reject at any reasonable level of significance in a likelihood ratio test the hypothesis that the heterogeneity controls don't matter. In general, factors that raise the recall hazard tend to reduce the new job hazard and vice versa. This is quite consistent with the search model with recall sketched in section II. The main exception is that nonwhites and females have significantly lower recall and new job hazards than do white males. The adverse outside labor market conditions faced by many nonwhites and females seem to depress their new job finding rate more than the increased job search effort related to lower recall prospects seems to increase it. Years of schooling appears to raise workers new job finding opportunities. Local labor market conditions as proxied by county unemployment rates reduce the new job hazard but have little effect on the recall hazard. The pattern of industry and occupation dummy coefficient estimates is consistent with theoretical predictions. Workers in durable goods industries have quite high recall hazards and quite low new job finding rates.

Another way to assess the effects of recall chances on new job search behavior is to compare the new job hazard function for workers with no recall possibility to that of those with a positive recall probability. The unemployment spell data from the PSID does identify whether a worker's unemployment spell was initiated by a plant closing. 111 plant closing observations have all the relevant data from which to estimate the basic model. I assume workers who lost their jobs through plant closings have no recall possibilities. Thus, they make no contribution to the recall part of the likelihood function.

The lack of a possibility of recall should raise the new job escape rate after controlling for heterogeneity factors. When the new job component of the likelihood function (equation (17)) is estimated with the plant closing sample added and a plant closing dummy variable added to the regressor list, the plant closing dummy comes in statistically significant and quite positive for the 
entire sample and for both the UI and no UI groups in isolation. For the entire sample, the plant closing dummy is estimated as .5907 with a standard error of .129 . The estimates of the other parameters do not change at all substantially. The results are quite similar for the UI and no UI groups when they are broken out separately. These estimates provide strong support for the hypothesis that greater recall prospects depress new job finding.

A summary of duration dependence parameter estimates in models with observed heterogeneity controls for the entire layoff sample, the layoff subsample with job tenure information, and the plant closing sample is presented in Table 10. Strong positive duration dependence consistent with a number of search theoretic models and with a model of workers learning about their recall prospects in a Bayesian manner is apparent in the new job finding rate for the UI recipients in the layoff sample. This positive duration dependence is hidden in the traditional single risk model specification for this group.

The recall rate appears to decline with unemployment duration. This may indicate true negative duration dependence or it may be related to the impact of uncontrolled heterogeneity. One scenario consistent with the estimated declining recall hazard and increasing new job hazard for UI recipients is that shocks to demand at the firm level may be heterogeneous and it may take time for firms and workers to determine the nature of a shock.

A particular example can help illustrate this point. Firms face two states of demand: high demand and low demand. Firms may choose to adjust to low demand states by placing some workers on layoff. Two types of shocks can knock firms into the low demand state: "transitory" shocks and "permanent" shocks. Recovery to the high demand state has a constant arrival rate. The recovery arrival rate is greater for transitory shocks than for permanent shocks. Firms and workers can't immediately determine whether downturns are transitory or permanent. The longer a low demand state lasts the more likely it will appear to be a "permanent" low demand state. The longer a worker remains on layoff the lower his or her perceived instantaneous recall probability. This induces a declining reservation wage and positive duration dependence in the new job finding rate. This heterogeneity in shocks is unlikely to be captured by individual and industry control variables 
and induces apparent negative duration dependence in the recall rate.

The large difference in the duration parameter estimates shown in Table 10 for the UI recipient and nonrecipient groups indicates that the limited duration of unemployment insurance has an important impact on the duration of layoff unemployment spells. Since previous job tenure is an important determinant of eligibility for UI benefits, it is important to note that the large differences in the UI and no UI group estimates remain even after controlling for months of tenure at previous job. The degree of positive duration dependence for UI recipients in the plant closing sample potentially indicates the impact of limited UI duration if one believes that these workers attach no possibility to recall through a plant reopening once they are dismissed. In this case, the greater degree of positive duration dependence for the UI recipients in the layoff sample can possibly be taken as a measure of the effect of changing perceptions about recall prospects on new job finding behavior.

\section{Conclusion}

The addition of the possibility of recalls to a job search model yields a competing risks model specification of the distribution of layoff unemployment spell durations. This specification requires a substantially different focus in an empirical analysis of layoff unemployment spell durations than that of traditional studies which tend to ignore the impacts of the recall process and simply analyze the overall unemployment to employment transition probability through a single risk model. It also requires a data set that allows the investigator to distinguish recalls from new job transitions.

An empirical analysis of a large sample of individual unemployment spells provides support for the predictions of job search models modified to take into account the impact of potential recall to a worker's previous employer. The competing risks model specification uncovers insights into the distribution of unemployment spell durations masked by the typical single risk approach to analyzing unemployment spell duration data. Strong positive duration dependence in the new job finding rate is uncovered for UI recipients in the competing risks specification. Comparisons of competing risks model and single risk model estimates indicate that inferences drawn from single risk models 
for samples including workers with nonnegligible recall prospects can be misleading.

The empirical estimates for the PSID indicate that recall prospects appear to substantially affect the behavior and labor market outcomes of laid-off workers. The recall hazard is found to increase with and the new job hazard is found to strongly decrease with job tenure.

Major differences are apparent in the sample hazard functions and in the estimated hazard functions with observed heterogeneity controls for UI recipient and nonrecipient groups. The recall and new job finding rates for UI recipients exhibit sharp increases in the intervals surrounding UI benefit exhaustion dates. Similar behavior is not evident in the hazard functions for UI nonrecipients. The differences in the estimated new job hazard for the UI recipient and nonrecipient groups provide support for the predictions of the job search model of Mortensen (1977) in which the limited duration of UI benefits is explicitly treated. The results provide strong evidience that the potential duration of UI benefits has an important impact on the workings of the layoff-recall process and on the search behavior of laid-off workers.

The basic theoretical and empirical framework developed in this paper can be extended to analyze the behavior of "displaced" workers. In this context, the worker's choice of whether to stay in his or her own market in hope of future improvements in opportunities as oppossed to undertaking an expensive move to another locale or region in search of better prospects is analogous to the laid-off workers decision between waiting for recall and undertaking costly search for an alternative job. This extension may prove useful in understanding the labor market in an economy subject to important geographic and sectoral shifts of economic activity. 


\section{References}

Barron, John M. and Wesley Mellow. "Search Efforts in the Labor Market." Journal of Human Resources 14 (1979): 389-404.

Bradshaw, T.F. and J.L. Scholl, "The Extent of Job Search During Layoff." Brookings Papers on Economic Activity. 1976, no. 2: 515-24.

Burdett, Kenneth and Dale T. Mortensen. "Labor Supply and Uncertainty." in R. Ehrenberg, ed., Research in Labor Economics, Vol. 2 London: JAI Press, 1981.

Clark, Kim B. and Lawrence H. Summers. "Labor Market Dynamics and Unemployment: A Reconsideration." Brookings Papers on Economic Activity. 1979, no. 1: 13-60.

Classen, Kathleen P. "Unemployment Insurance and Job Search." in S. Lippman and J.J. McCall, eds., Studies in the Economics of Search. New York: North Holland, 1979.

Corson, Walter and Walter Nicholson. "An Analysis of UI Recipients' Unemployment Spells." Unemployment Insurance Service Occasional Paper No. 83-1, U.S. Department of Labor, Employment and Training Administration, 1983.

Cox, D.R. "Regression Models and Life Tables." Journal of the Royal Statistical Society Series B, 34 (1972): 187-202.

Ehrenberg, R.G. and R.L. Oaxaca. "Unemployment Insurance, Duration of Unemployment, and Subsequent Wage Growth." American Economic Review 66 (1976): 754-766.

Farber, Henry S. "Are Quits and Firings Actually Different Events?: A Competing Risks Model of Job Duration." Mimeo. MIT, 1980.

Feldstein, Martin S. "The Importance of Temporary Layoffs: An Empirical Analysis." Brookings Papers on Economic Activity 1975, no. 3: 725-744.

Feldstein, Martin S. "Temporary Layoffs in the Theory of Unemployment." Journal of Political Economy 84 (1976): 837-57.

Flinn, C. and J.J. Heckman. "Models for the Analysis of Labor Force Dynamics." in G. Rhodes and R. Basmenn, eds., Advances in Econometrics. London: JAI Press, 1982a.

Flinn, C. and J.J. Heckman. "New Methods for Analyzing Structural Models of Labor Force Dynamics." Journal of Econometrics 18 (1982b): 115-68.

Ham, John C. and Samuel A. Rea. "Unemployment Insurance and Male Unemployment Duration in Canada." Mimeo, University of Toronto, March 1985

Heckman, J.J. and B. Singer. "Econometric Duration Analysis." Journal of Econometrics 24 (1984a): 63-132. 
Heckman, J.J. and B. Singer. "A Method for Minimizing the Impact of Distributional Assumptions in Econometric Models for Duration Data." Econometrica 52 (1984b): 271-320.

Kalbfleisch, John D. and Ross Prentice. The Statistical Analysis of Failure Time Data. New York: Wiley, 1980.

Katz, Lawrence. "Worker Mobility and Unemployment," Ph.D. Dissertation, MIT, 1985.

Kiefer, N. and G. Neumann. "An Empirical Job Search Model with a Test of the Constant Reservation Wage Hypothesis." Journal of Political Economy 87 (1979): 89-108.

Lancaster, Tony. "Econometric Methods for the Duration of Unemployment." Econometrica 47 (1979): 939-56.

Lilien, David. "The Cyclical Importance of Temporary Layoffs." Review of Economics ad Statistics 62 (1980): 24-31.

McCall, J.J. "Economics of Information and Job Search." Quarterly Journal of Economics 84 (1970): $113-26$.

Mortensen, Dale T. "Unemployment Insurance and Job Search Decisions." Industrial and Labor Relations Review 30 (1977): 595-612.

Mortensen, Dale T. "Job Search and Labor Market Analysis." MEDS Discussion Paper No. 594, Northwestern University, April 1984.

Narendranathan, W.; S. Nickell and J. Stern. "Unemployment Benefits Revisited." Economic Journal 95 (1985): 307-329.

Pissarides, Christopher A. "Job Search and the Duration of Layoff Unemployment." Quarterly Journal of Economics 97 (1982): 595-612.

Sider, Hal. "Unemployment Duration and Incidence: 1968-82." American Economic Review 75 (1985): 465-472.

Solon, Gary. "Work Incentive Effects of Taxing Unemployment Benefits." Econometrica 53 (1985): 295-306.

Survey Research Center. A Panel Study of Income Dynamics: Wave XV Documentation. Ann Arbor, Mi.: University of Michigan, 1984.

Topel, Robert H. "On Layoffs and Unemployment Insurance." American Economic Review 73 (1983): 541-559.

Topel, Robert H. "Equilibrium Earnings, Turnover, and Unemployment: New Evidence." Journal of Labor Economics 2 (1984): 500-522.

Unemployment Benefit Advisors, Inc. Highlights of State Unemployment Compensation Law', January 1982. Washington, D.C.: UBA, Inc., 1982. 
U.S. Department of Labor, Employment and Training Administration. Unemployment Insurance Claims. Washington, D.C.: U.S. Government Printing Office, 1983.

White, Barbara A. "Optimal Strategies for Workers on Temporary Layoff." Economic Inquiry 21 (1983): 520-544. 
Table 1: Variable Definitions and Means (Standard Deviations) of the Data-PSID Layofi Unemployment Spell Sample

Variable

Duration

Recall

New Job

Censored

Age

NW

$\mathrm{Fe}$

$\mathrm{Ma}$

Ed

CUN

UI

Industry

Dummy Variables (*)

Treq

ODUR

NDUR

Trade

Trans

Mining

Serv

Con

Occupation

Dummy Variables (*)
Description

observed unemployment spell duration in weeks

$=1$ if spell ended in recall

Mean (Standard Deviation)

$=1$ if spell ended in taking

of a new job

$=1$ if spell duration

is censored

age in years

$=1$ if nonwhite

.506

$=1$ if female

$=1$ if married

$=$ years of schooling

$=$ county unemployment rate

7.70

(2.55)

$=1$ if worker received unemployment insurance benefits during some part of spell

$=1$ if in transportation equipment

$=1$ if in other durable goods

manufacturing

$=1$ if in nondurable goods manufacturing

$=1$ if in wholesale or retail trade

$=1$ if in transportation or public

.080

$=1$ if in mining or agriculture

$=1$ if in services

$=1$ if in construction 
Table 1: Variable Definitions and Means (Standard Deviations) of the Data-PSID Layoff Unemployment Spell Sarnple

\begin{tabular}{|c|c|c|}
\hline Variable & Description & $\begin{array}{c}\text { Mean } \\
\text { (Standard Deviation) }\end{array}$ \\
\hline Labor & $=1$ if laborer or operative & .508 \\
\hline Craft & $=1$ if craftsmen or kindred worker & .223 \\
\hline Cler & $\begin{array}{l}=1 \text { if clerical, services or } \\
\text { sales worker }\end{array}$ & .186 \\
\hline Manager & $=1$ if manager & .044 \\
\hline Prof & $\begin{array}{l}=1 \text { if professional or technical worker } \\
\qquad n=1055\end{array}$ & .039 \\
\hline
\end{tabular}

(*) Industry and Occupation refer to job from which unemployment spell initiated. 
Table 2: Sample Hazard Function Estimates - Entire Sample PSID Data

\begin{tabular}{|c|c|c|c|c|}
\hline Weeks & $\begin{array}{c}\text { Overall Unemployment } \\
\text { Hazard }\end{array}$ & $\begin{array}{l}\text { Recall } \\
\text { Hazard }\end{array}$ & $\begin{array}{l}\text { New Job } \\
\text { Hazard }\end{array}$ & $\begin{array}{c}\text { Population } \\
\text { at Risk } \\
\end{array}$ \\
\hline $1-4$ & .354 & .307 & .047 & 1055 \\
\hline $5-8$ & .183 & .129 & .054 & 682 \\
\hline $9-12$ & .160 & .106 & .054 & 557 \\
\hline $13-16$ & .161 & .109 & .052 & 466 \\
\hline $17-20$ & .120 & .056 & .064 & 375 \\
\hline $21-24$ & .114 & .060 & .054 & 299 \\
\hline $25-28$ & .165 & .082 & .082 & 243 \\
\hline $29-32$ & .084 & .022 & .061 & 179 \\
\hline $33-36$ & .060 & .013 & .047 & 150 \\
\hline $37-40$ & .123 & .046 & .077 & 130 \\
\hline $41-44$ & .058 & .038 & .019 & 104 \\
\hline $45-48$ & .011 & .000 & .011 & 94 \\
\hline 49-52 & .078 & .011 & .067 & 90 \\
\hline $53-56$ & .034 & .000 & .034 & 59 \\
\hline $57-60$ & .018 & .000 & .018 & 55 \\
\hline
\end{tabular}


Table 3: Sample Hazard Function Estimates - Ul=1 Sample PSID Data

\begin{tabular}{|c|c|c|c|c|}
\hline Weeks & $\begin{array}{c}\text { Overall Unemployment } \\
\text { Hazard }\end{array}$ & $\begin{array}{l}\text { Recall } \\
\text { Hazard }\end{array}$ & $\begin{array}{l}\text { New Job } \\
\text { Hazard }\end{array}$ & $\begin{array}{l}\text { Population } \\
\text { at Risk }\end{array}$ \\
\hline $1-4$ & .343 & .315 & .028 & 671 \\
\hline $5-8$ & .184 & .129 & .054 & 441 \\
\hline $9-12$ & .161 & .106 & .056 & 360 \\
\hline $13-16$ & .166 & .116 & .050 & 302 \\
\hline $17-20$ & .144 & .066 & .078 & 243 \\
\hline $21-24$ & .114 & .054 & .059 & 185 \\
\hline $25-28$ & .227 & .120 & .107 & 150 \\
\hline $29-32$ & .123 & .028 & .094 & 106 \\
\hline $33-36$ & .083 & .012 & .071 & 84 \\
\hline $37-40$ & .192 & .074 & .118 & 68 \\
\hline $41-44$ & .082 & .041 & .041 & 49 \\
\hline $45-48$ & .024 & .000 & .024 & 42 \\
\hline $49-52$ & .128 & .000 & .128 & 39 \\
\hline $53-56$ & .087 & .000 & .087 & 23 \\
\hline $57-60$ & .053 & .000 & .053 & 19 \\
\hline
\end{tabular}


Table 4: Sample Hazard Function Estimates - U]=0 Sample PSID Data

\begin{tabular}{|c|c|c|c|c|}
\hline Weeks & $\begin{array}{c}\text { Overall Unemployment } \\
\text { Hazard }\end{array}$ & $\begin{array}{l}\text { Recall } \\
\text { Hazard }\end{array}$ & $\begin{array}{l}\text { New Job } \\
\text { Hazard }\end{array}$ & $\begin{array}{c}\text { Population } \\
\text { at Risk } \\
\end{array}$ \\
\hline $1-4$ & .372 & .294 & .078 & 384 \\
\hline $5-8$ & .183 & .129 & .054 & 241 \\
\hline $9-12$ & .157 & .107 & .051 & 197 \\
\hline $13-16$ & .152 & .098 & .055 & 164 \\
\hline $18-20$ & .076 & .038 & .038 & 132 \\
\hline $21-24$ & .114 & .070 & .044 & 114 \\
\hline $25-28$ & .065 & .022 & .043 & 93 \\
\hline $29-32$ & .027 & .014 & .014 & 73 \\
\hline $33-36$ & .030 & .015 & .015 & 66 \\
\hline $38-40$ & .048 & .016 & .032 & 62 \\
\hline $41-44$ & .036 & .036 & .000 & 55 \\
\hline $45-48$ & .000 & .000 & .000 & 52 \\
\hline $49-52$ & .039 & .020 & .020 & 51 \\
\hline $53-56$ & .000 & .000 & .000 & 36 \\
\hline $57-60$ & .000 & .000 & .000 & 36 \\
\hline
\end{tabular}


Table 5: Single Risk Model with Observed Heterogeneity Controls PSID Data

\begin{tabular}{|c|c|c|}
\hline Variable & UI=1 Sample & $\mathrm{UI}=0$ Sample \\
\hline Constant & $\begin{array}{c}-2.763 \\
(.381)\end{array}$ & $\begin{array}{r}-1.028 \\
(.522)\end{array}$ \\
\hline Age & $\begin{array}{l}.0171 \\
(.004)\end{array}$ & $\begin{array}{r}-.0006 \\
(.006)\end{array}$ \\
\hline $\mathrm{Ed}$ & $\begin{array}{l}.014 \\
(.022)\end{array}$ & $\begin{array}{l}.043 \\
(.030)\end{array}$ \\
\hline NW & $\begin{array}{c}-.409 \\
(.088)\end{array}$ & $\begin{array}{l}-.363 \\
(.138)\end{array}$ \\
\hline $\mathrm{Fe}$ & $\begin{array}{l}-.196 \\
(.138)\end{array}$ & $\begin{array}{l}-.366 \\
(.169)\end{array}$ \\
\hline $\mathrm{Ma}$ & $\begin{array}{l}-.042 \\
(.120)\end{array}$ & $\begin{array}{l}.341 \\
(.143)\end{array}$ \\
\hline CUN & $\begin{array}{l}-.010 \\
(.015)\end{array}$ & $\begin{array}{l}-.073 \\
(.021)\end{array}$ \\
\hline Treq & $\begin{array}{l}-.012 \\
(.413)\end{array}$ & $\begin{array}{l}-.820 \\
(.373)\end{array}$ \\
\hline ODUR & $\begin{array}{l}.089 \\
(.125)\end{array}$ & $\begin{array}{l}-.229 \\
(.218)\end{array}$ \\
\hline Trade & $\begin{array}{l}-.179 \\
(.207)\end{array}$ & $\begin{array}{l}-.499 \\
(.245)\end{array}$ \\
\hline Trans & $\begin{array}{l}-.326 \\
(.186)\end{array}$ & $\begin{array}{l}-.338 \\
(.253)\end{array}$ \\
\hline Mining & $\begin{array}{l}.263 \\
(.340)\end{array}$ & $\begin{array}{l}-.173 \\
(.253)\end{array}$ \\
\hline Serv & $\begin{array}{l}-.351 \\
(.207)\end{array}$ & $\begin{array}{l}-.536 \\
(.236)\end{array}$ \\
\hline Con & $\begin{array}{l}-.201 \\
(.163)\end{array}$ & $\begin{array}{l}.113 \\
(.216)\end{array}$ \\
\hline Craft & $\begin{array}{l}-.011 \\
(.107)\end{array}$ & $\begin{array}{l}.109 \\
(.175)\end{array}$ \\
\hline Cler & $\begin{array}{l}-.019 \\
(.170)\end{array}$ & $\begin{array}{l}.401 \\
(.204)\end{array}$ \\
\hline Prof & $\begin{array}{l}.066 \\
(.313)\end{array}$ & $\begin{array}{l}1.037 \\
(.336)\end{array}$ \\
\hline Manager & $\begin{array}{l}-.117 \\
(.413)\end{array}$ & $\begin{array}{l}.568 \\
(.277)\end{array}$ \\
\hline Duration & $\begin{array}{c}.854 \\
(.036)\end{array}$ & $\begin{array}{c}.722 \\
(.050)\end{array}$ \\
\hline $\ln \mathrm{L}$ & -2157.61 & -1134.03 \\
\hline
\end{tabular}

The base industry is NDUR; the base occupation is Labor; the numbers in parentheses are asymptotic standard errors. 
Table 6: Competing Risks Model with Observed Heterogeneity Controls UI $=1$ Sample $(n=671)$ - PSID Data

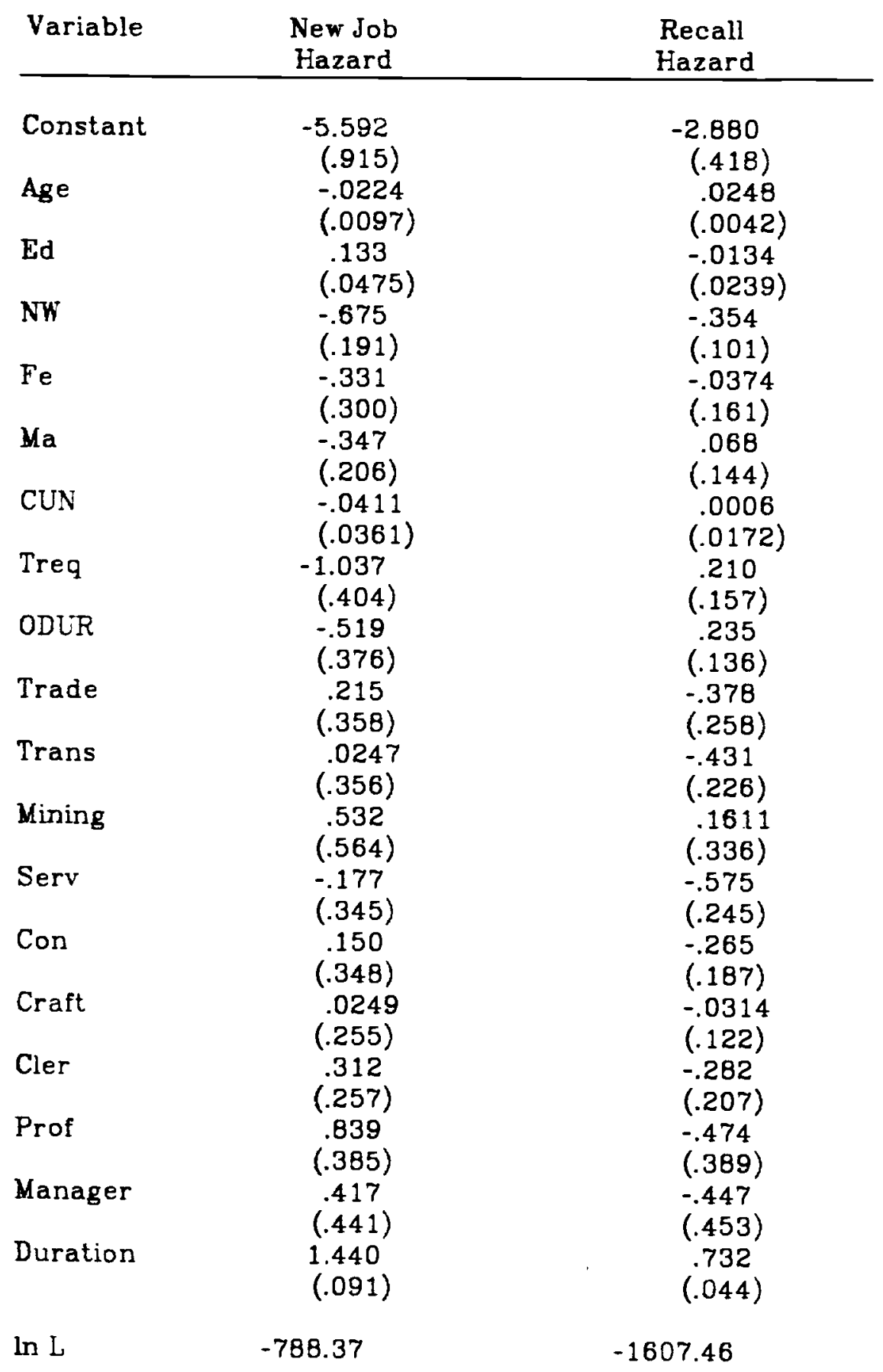

The base industry is NDUR; the base occupation is Labor; the numbers in parenthses are asymptotic standard errors. 
Table 7: Competing Risks Model with Observed Heterogeneity Controls UI $=0$ Sample $(n=384)$ - PSID Data

\begin{tabular}{|c|c|c|}
\hline Variable & $\begin{array}{c}\text { New Job } \\
\text { Hazard }\end{array}$ & $\begin{array}{c}\text { Recall } \\
\text { Hazard }\end{array}$ \\
\hline Constant & $\begin{array}{r}-1.016 \\
(.106)\end{array}$ & $\begin{array}{c}-1.918 \\
(.641)\end{array}$ \\
\hline Age & $\begin{array}{l}-.0475 \\
(.0141)\end{array}$ & $\begin{array}{l}.0129 \\
(.0072)\end{array}$ \\
\hline $\mathbf{E d}$ & $\begin{array}{l}-.0710 \\
(.0607)\end{array}$ & $\begin{array}{l}-.0264 \\
(.0357)\end{array}$ \\
\hline NW & $\begin{array}{l}-.669 \\
(.268)\end{array}$ & $\begin{array}{l}-.251 \\
(.160)\end{array}$ \\
\hline $\mathrm{Fe}$ & $\begin{array}{l}-.616 \\
(.209)\end{array}$ & $\begin{array}{l}-.266 \\
(.331)\end{array}$ \\
\hline Ma & $\begin{array}{l}.528 \\
(.268)\end{array}$ & $\begin{array}{c}.322 \\
(.168)\end{array}$ \\
\hline $\mathrm{CUN}$ & $\begin{array}{l}-.138 \\
(.0440)\end{array}$ & $\begin{array}{l}-.0495 \\
(.0274)\end{array}$ \\
\hline Treq & $\begin{array}{l}-.353 \\
(.840)\end{array}$ & $\begin{array}{l}.960 \\
(.435)\end{array}$ \\
\hline ODLR & $\begin{array}{l}.333 \\
(.528)\end{array}$ & $\begin{array}{l}-.433 \\
(.255)\end{array}$ \\
\hline Trade & $\begin{array}{l}.466 \\
(.491)\end{array}$ & $\begin{array}{c}-1.023 \\
(.323)\end{array}$ \\
\hline Trans & $\begin{array}{l}.0924 \\
(.565)\end{array}$ & $\begin{array}{l}-.509 \\
(.296)\end{array}$ \\
\hline Mining & $\begin{array}{l}-.426 \\
(.652)\end{array}$ & $\begin{array}{l}-.131 \\
(.304)\end{array}$ \\
\hline Serv & $\begin{array}{l}.0295 \\
(.492)\end{array}$ & $\begin{array}{l}-.734 \\
(.280)\end{array}$ \\
\hline Con & $\begin{array}{l}-.420 \\
(.572)\end{array}$ & $\begin{array}{l}.176 \\
(.253)\end{array}$ \\
\hline Craft & $\begin{array}{l}.133 \\
(.373)\end{array}$ & $\begin{array}{l}.128 \\
(.204)\end{array}$ \\
\hline Cler & $\begin{array}{l}.918 \\
(.378)\end{array}$ & $\begin{array}{c}.170 \\
(.250)\end{array}$ \\
\hline Prof & $\begin{array}{l}1.421 \\
(.563)\end{array}$ & $\begin{array}{c}.871 \\
(.389)\end{array}$ \\
\hline Manager & $\begin{array}{l}1.111 \\
(.472)\end{array}$ & $\begin{array}{l}.407 \\
(.589)\end{array}$ \\
\hline Duration & $\begin{array}{l}.881 \\
(.109)\end{array}$ & $\begin{array}{c}.679 \\
(.059)\end{array}$ \\
\hline $\ln L$ & -425.19 & -854.88 \\
\hline
\end{tabular}

The base industry is NDUR; the base occupation is Labor; the numbers in parentheses are asymptotic stadard errors. 
Table 8: Modified Competing Risks Model Allowing Discrete

Spikes at 26 and 39 Weeks - UI $=1$ Sample $(n=6>1)$

PSID Data

\begin{tabular}{lcc} 
Variable & $\begin{array}{c}\text { New Job } \\
\text { Hazard }\end{array}$ & $\begin{array}{c}\text { Recall } \\
\text { Hazard }\end{array}$ \\
\hline Duration & 1.371 & .713 \\
$\pi_{1}$ & $(.095)$ & $(.046)$ \\
& 1.750 & 1.436 \\
$\pi_{2}$ & $(.289)$ & $(.298)$ \\
& 1.019 & .849 \\
ln $\mathrm{L}$ & $(.599)$ & $(.591)$ \\
& &
\end{tabular}

Controls for race. sex, education, marital status, age, county unemployment rate, industry and occupation and a constant are also included.

Table 9: Competing Risks Model with Observed Heterogeneity

Controls - Job Tenure Sub-Sample $(n=395)$

PSID Data

\begin{tabular}{lcc} 
Variable & $\begin{array}{c}\text { New Job } \\
\text { Hazard }\end{array}$ & $\begin{array}{c}\text { Recall } \\
\text { Hazard }\end{array}$ \\
\hline Constant & & \\
& -4.899 & -2.526 \\
$(1.120)$ & $(.562)$ \\
Age & -.00477 & .00091 \\
& $(.0131)$ & $(.0079)$ \\
Job Tenure & -.0156 & .0058 \\
(in months) & $(.0047)$ & $(.00084)$ \\
UI & -.177 & -.511 \\
Duration & $(.254)$ & $(.158)$ \\
& 1.241 & .809 \\
& $(.111)$ & $(.060)$ \\
In L & & -907.76
\end{tabular}

Controls are also included for race, sex, education. marital status, county unemployment rate, industry, and occupation. The numbers in parentheses are asymptotic
standard errors. 
Table 10: Summary of Duration Dependence Parameter Estimates for Models with Observed Heterogeneity Controls

Competing Risks Specification

Single Risk Specification

Recall Hazard New Job Hazard

Overall Hazard

Layoff Sample

\begin{tabular}{lcc}
$\begin{array}{l}\text { Entire Sample } \\
(\mathrm{n}=1055)\end{array}$ & $\begin{array}{l}.694 \\
(.035)\end{array}$ & $\begin{array}{l}1.138 \\
(.063)\end{array}$ \\
$\mathrm{UI}=1$ & .732 & 1.440 \\
$(\mathrm{n}=671)$ & $(.044)$ & $(.091)$ \\
$\mathrm{UI}=0$ & .679 & .881 \\
$(\mathrm{n}=384)$ & $(.059)$ & $(.109)$ \\
Job Tenure & & \\
Layoff Sample & & \\
\hline $\begin{array}{l}\mathrm{UI}=1 \\
(\mathrm{n}=271)\end{array}$ & & \\
& .816 & $(.627$ \\
$\mathrm{UI}=0$ & $(.074)$ & \\
$(\mathrm{n}=118)$ & & .927 \\
& .779 & $(.169)$
\end{tabular}

Plant Closing

Sample (*)

$\mathrm{UI}=1$

$(n=52)$

$\mathrm{UI}=0$

$(\mathrm{n}=59)$

.784

(.029)

.854

(.036)

.722

$(.050)$

Numbers in parentheses are asymptotic standard errors.

(*). No industry and occupation dummies are included as control variables in the plant closing sample estimates because of the small sample sizes. 
FIGLRE 1

\section{Sample Fazard Functions - Intire Sample}

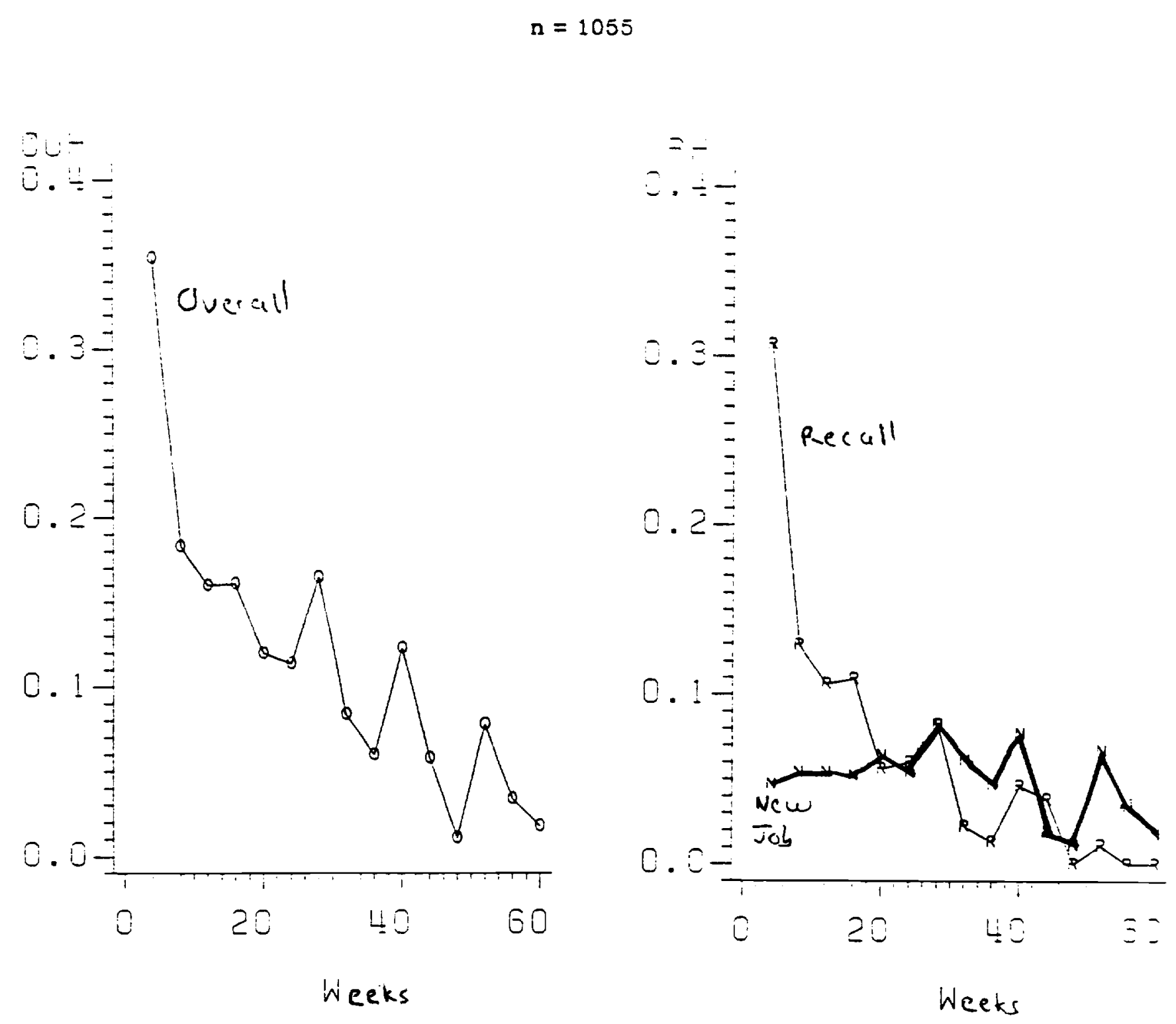


FIGLRE 2

Sample Hazard Functions - $U T=1$ Sample

$$
\mathrm{n}=571
$$
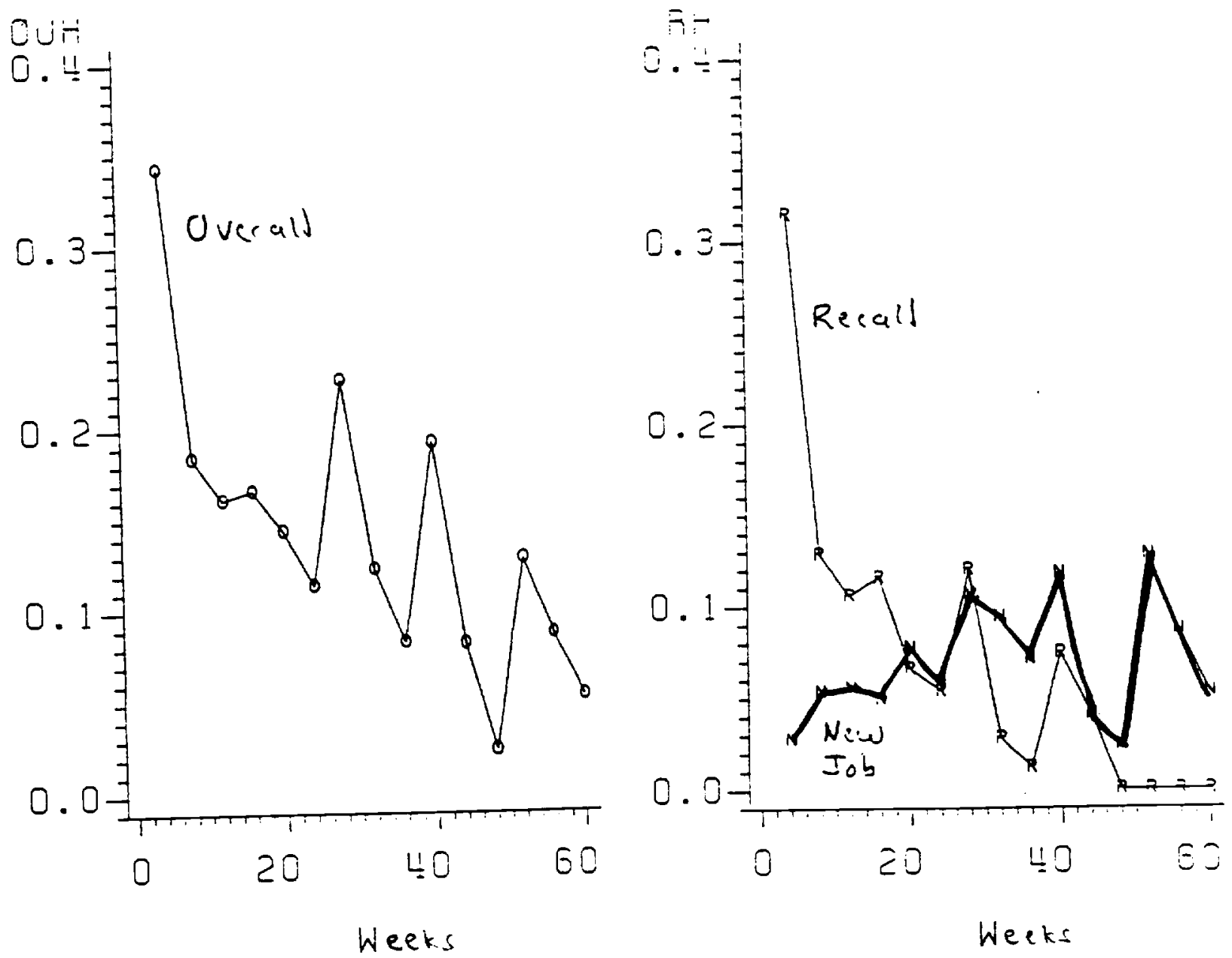
FIGLRE 3

Sample Hazard Functions $-U I=0$ Sampie

$$
n=384
$$
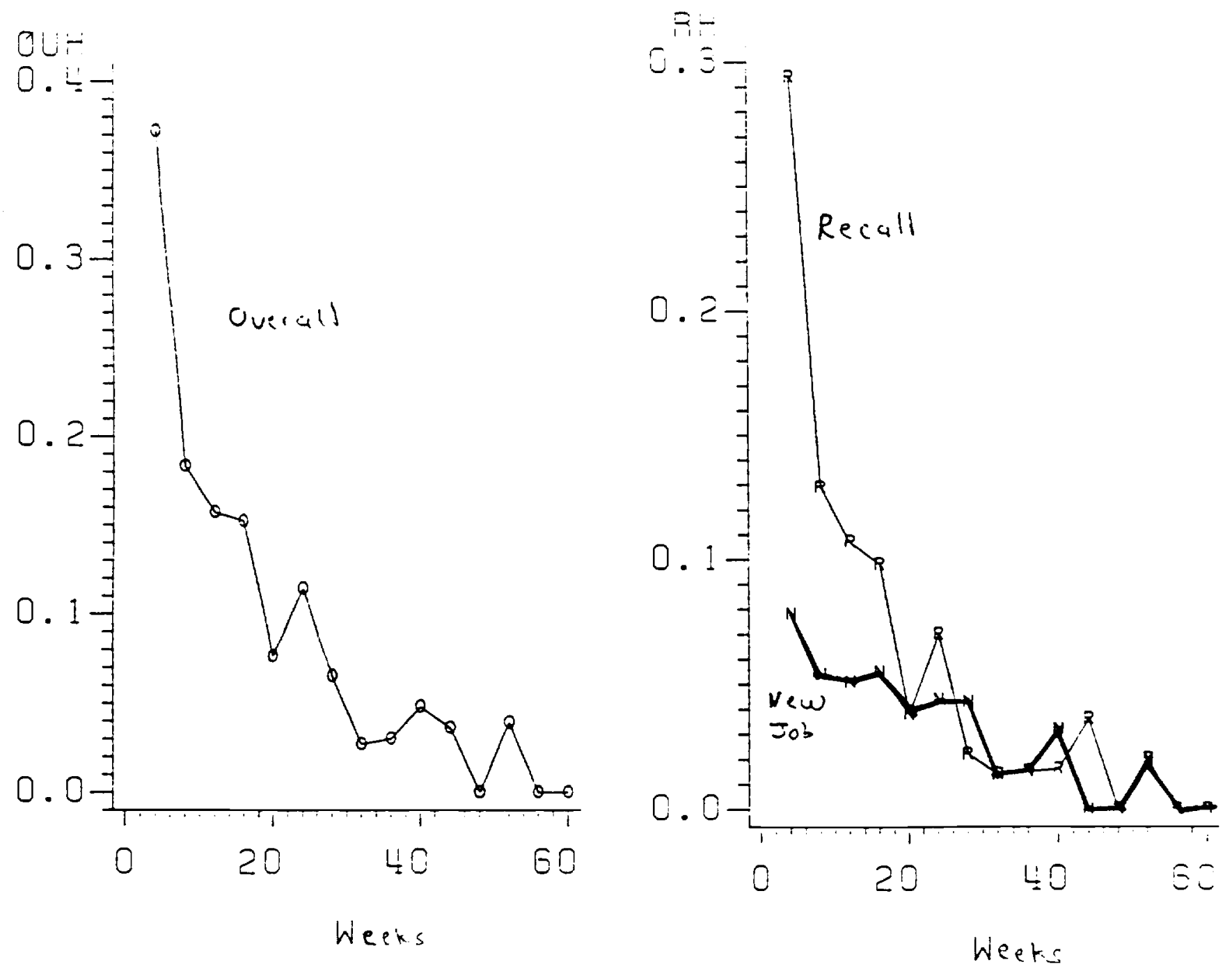


\section{APPENDIX:POTENTIAL BIASES ASSOCIATED WITH THE PSID SAMPLING SCHEME ${ }^{1}$}

The sampling framework for unemployment spells in the PSID does not yield a random sample of layoff unemployment spells. The likely direction and magnitude of biases in estimating the distribution of layoff unemployment spell durations from a sample generated by the PSID sampling scenario are analyzed in this Appendix.

An unemployment spell is picked up by waves 14 and 15 of the PSID only if it is an individual's last unemployment spell that at least at some point overlaps the calendar year previous to an interview. I analyze the implications of this sampling scheme under the assumption that employment and unemployment spells have independent densities. A grasp of the magnitude of the potential biases is gained by analyzing the illustrative, although far from general, case of employment and unemployment spells being independent Poisson processes. The analysis focuses on estimating the overall unemployment escape rate.

The nature of the sampling procedure means that correcting the likelihood function requires information on the distribution of employment spell durations which because of temporary layoffs is not the same as a job tenure distribution. The likelihood function correction is complicated further in a competing risks specification. These additional difficulties and data requirements have led me to focus on an analysis of the degree of bias in uncorrected likelihood function estimates rather than attempt to estimate a model with a full likelihood function correction.

An unemployment spell starting at some time $t$ before the end of the year previous to the interview makes it into the sample only if the spell does not terminate before the start of the year previous to the interview and if the individual does not have another unemployment spell after the end of the first spell that begins before the end of the year previous to the interview. The longer an unemployment spell lasts for any given starting date before the end of the previous year the less

1. Jeff Harris provided invaluable assistance in the preperation of this Appendix. 
likely is it that the ensuing employment spell will terminate before the end of the sampling frame. This follows if unemployment and employment spells have independent densities. Thus, the longer an unemployment spell lasts for a given starting date, the more likely it is to enter the sample. This framework oversamples long spells leading to an upward bias in the estimate of expected unemployment spell duration and a downward bias in the estimate of the escape rate from unemployment.

The formal analysis precedes with the following definitions:

$t=$ start date of an unemployment spell (in reverse time)

$y=$ unemployment spell duration (in forward time)

I let $x$ denote the event that an unemployment spell enters the sample, and I let $g\left({ }^{\circ}\right)$ denote a general density function. I shall also let $\pi($ ) denote a general density function.

The key quantiiy that needs to be determined for the analysis is the density of unemployment spell durations conditional on a spell entering the sample $g(y \mid x)$. Note,

$$
g(y \mid x)=\int_{f}^{\infty} g(y, t \mid x) d t
$$

where

$$
g(y, t \mid x)=\frac{g(x \mid y, t) \pi(y \mid t) \pi(t)}{g(x)}
$$

and

$$
g(x)=\int_{0}^{\infty} \int_{0}^{\infty} g(x \mid y, t) \pi(y \mid t) \pi(t) d t d y .
$$

$\pi(t)$ is assumed to be given by the uniform density. ${ }^{2}$

I let unemployment spell durations have density $f(y)$, and I let employment spell durations have density $h(z)$ where $z$ is the length of an employment spell. The associated cumulative distribution function for emplyment spells is given by $H(z)$. This means

$$
\pi(y \mid t)=f(y) .
$$

$\overline{2 .}$ This assumption holds in a steady state environment. 
Additionally, I define

$t^{*}=$ cutoff date for entry into sample.

Any spell that terminates before $t^{*}$ does not make it into the sample. The PSID sampling framework represents the case of $t^{*}=52$ when time is measured in weeks and the further a stan date is in the past the larger the value of $t$.

The derivation of $g(y \mid x)$ precedes as follows:

$$
\begin{aligned}
& g(x \mid y, t)= \begin{cases}1 & \text { if } y \geq t \\
1-H(t-y) & \text { if } t-t^{*}<y<t \\
0 & \text { if } y<t-t^{*}<t\end{cases} \\
& g(x)=\int_{f}^{\infty} g(x \mid y, t) f(y) d t d y \\
& \quad=\phi+\int_{0}^{\infty} f(y) \int_{y}^{y+t}[1-H(t-y)] d t d y
\end{aligned}
$$

For the purpose of producing results that will allow an analysis of the magnitude of potential biases, I assume that transitions from employment to unemployment follow a Poisson process with parameter $u=\frac{1}{\theta}$. Thus,

$$
\begin{aligned}
& H(z)=1-e^{-u t} . \\
& \int_{y}^{y+t^{\circ}}[1-H(t-y)] d t=\theta\left[1-e^{-t^{*} u}\right] .
\end{aligned}
$$

This implies that

$$
g(x)=\phi+\theta\left[1-e^{-i^{*} u}\right]
$$

and

$$
g(y \mid x)=\int_{\phi+\theta\left[1-e^{-t^{*} u}\right]}^{\infty} \frac{1}{\phi \mid y, t) f(y) d t .} .
$$

This yields

$$
g(y \mid x)=\frac{y+\theta\left[1-e^{-\frac{i^{*}}{\theta}}\right]}{\phi+\theta\left[1-e^{-\frac{i^{*}}{\theta}}\right]} f(y)
$$


and

$$
E(y \mid x)=\phi+\frac{\operatorname{var}(y)}{\phi+\theta\left[1-e^{-\frac{t^{\theta}}{\theta}}\right]} .
$$

Thus, $E(y \mid x)>E(y)$.

This sampling scheme oversamples long spells and leads to too large an estimate of the expected unemployment duration. The bias in the estimate of the expected unemployment spell duration is given by

$$
\begin{gathered}
\text { Bias }=\frac{\phi^{2}}{\phi+\theta\left[1-e^{-\frac{i^{*}}{\theta}}\right]} \\
\frac{\partial \text { Bias }}{\partial t^{*}}<0 \text { and } \frac{\partial \text { Bias }}{\partial \theta}<0 .
\end{gathered}
$$

The further assumption that transitions from unemployment to employment follow a Poisson process with parameter $\frac{1}{\phi}$ yields a hazard function conditional on the sampling process of

$$
h(y \mid x)=\frac{\frac{1}{\phi}\left[y+\theta\left(1-e^{-\frac{t^{*}}{\theta}}\right)\right]}{\phi+\theta\left(1-e^{-\frac{t^{*}}{\theta}}\right)+y} .
$$

This differs from the true hazard for the population $h(y)=1 / \phi$. Thus,

$$
h(y \mid x)<h(y) \text { and } \frac{\partial h(y \mid x)}{\partial y}>0 .
$$

Spurious positive duration dependence is generated.

An analysis of realistic values for $\theta$ and $\phi$ reveals that the bias in the estimated duration for data filtered through this sampling procedure could be as high as 3 to 5 weeks. On the other hand, the degree of spurious positive duration dependence created by the sampling scheme is not very great under reasonable assuptions about $\phi$ and $\theta$. It does not seem possible that the sampling scheme could produce anywhere near the degree of positive duration dependence estimated for UI recipient groups from the PSID. Thus, these results indicate true positive duration dependence.

The magnitude of potential biases linked to the sampling frame can be illuminated by a rea- 
sonable example. In this example, I assume $t^{*}=52, \phi=16$, and $\theta\left[1-\exp \left(-t^{*} / \theta\right)\right]=40 .^{3}$

A sample generated by this scheme with these underlying population parameter values would lead to an estimated $\hat{\phi}$ of approximately 20.57 . Thus, a 4.6 week upward bias in estimating $E(y)$ is generated. The extent of duration dependence created in terms of the elasticity of the hazard with respect to spell duration can be evaluated through the use of the following:

$$
e_{h, y}=\frac{\partial \ln h(y \mid x)}{\partial \ln y}=\frac{y \phi}{\left[\phi+\theta\left(1-e^{-l^{\dagger} / \theta}\right)+y\right]\left[y+\theta\left(1-e^{-i^{*} / \theta}\right)\right]}
$$

Evaluated at the mean spell duration, one attains $e_{h, y}=.06$. As long as the reasonable assumption is maintained that employment spells are longer than unemployment spells (i.e. the unemployment rate for the group of interest is under 50 percent), one cannot generate values of spurious positive duration dependence large enough to account for the estimates presented in section $V$. Thus, the estimates of duration parameters for UI recipients of the PSID sample do not appear to be merely an artifact of the sampling scheme.

$\overline{\text { 3. In other words, } \theta}$ is approximately 95 weeks. 